\title{
Temperature-independent precipitation amount proxy by using boron isotope of land snail shells in the East Asian Monsoon area
}

\author{
CHENGLONG LI, XUEFEN SHENG AND HAI-ZHEN WEI
}

School of Earth Sciences and Engineering, Nanjing University

Presenting Author:mg1529045@smail.nju.edu.cn

The boron isotope of biogenic calcium carbonate like coral, foraminifera have been used as $\mathrm{pCO}_{2}$ reconstruction, as a probe into the biomineralization process and identifying ocean acidification [1]. However, information about the boron isotope composition of land snail shell, which is preserved by nearly continuous dust accumulation in Chinese Loess Plateau (CLP), is rare. Previous studies showed that the boron isotopic composition of paleo-rainwater can be used as a potential proxy for tracing changes in the East Asian monsoon (EAM) since the mid-Pleistocene [2]. Comparing to inorganic $\mathrm{CaCO}_{3}$, land snail shells could be preserved well with original geochemistry data in CLP. Boron isotope compositions of land snail shells $\left(\delta^{11} \mathrm{~B}_{\text {snail }}\right)$ are used as temperature-independent precipitation proxy in this study, by analyzing modern field shells collected in the EAM and culturing shells in the laboratory. The results demonstrate that the contribution of the water in the food is the main source for $\delta^{11} \mathrm{~B}_{\text {snail }}$ during culturing by using mass equation calculation, which is consistent with the data of the field land snail. A positive relationship between the $\delta^{11} \mathrm{~B}_{\text {snail }}$ of field snail shells and Mean Annual Precipitation amount has been established, and $\delta^{11} \mathrm{~B}_{\text {snail }}$ is insensitive to the variation of temperature. Hence $\delta^{11} \mathrm{~B}_{\text {snail }}$ could be used as the paleo-precipitation amount proxy for reconstructing EAM.

[1] Wei et al (2021), ESR 215, 103546.

[2] Lei et al (2021), EPSL 561, 116826. 